The Squared Horizon: Frames and Trajectories of Paul Virilio

\title{
REWRITING MODERNITY
}

\section{Topographical and Topological Variations \\ in Paul Virilio's Le futurisme de l'instant}

Enda McCaffrey

\begin{abstract}
This article rereads Paul Virilio, drawing on the distinction between topography and topology to argue a case for Virilio as a rewriter of modernity. Invoking Jean-François Lyotard's notion of rewriting modernity as an unbroken process of accumulation founded on affective life in "Re-writing Modernity" and "Argumentation and Presentation: The Foundation Crisis," it enlists topology as a horizontal spatial structure that enables us to rethink space, time, and modernity outside the limits of the "squared horizon," where the "squared horizon" is viewed as a spatial and textual metaphor for framing perspectives on the past, present, and future. The analysis deconstructs the topography of the "squared horizon" as a relationality in an unfolding continuum, where spaces exist ontologically and where the immaterial forces of the dromospheric and the atmospheric generate a relational and historical connectedness.
\end{abstract}

Keywords Jean-François Lyotard, modernity, rewriting, topology, topography, relationality

In the differend, something "asks" to be put into phrases, and suffers from the wrong of not being able to be put into phrases right away. This is when the human beings who thought they could use language as an instrument of communication learn through the feeling of pain which accompanies silence (and of pleasure which accompanies the invention of a new idiom) that they are summoned by language, not to augment to their profit the quantity of information communicable through existing idioms, but to recognise that what remains to be phrased exceeds what they can presently phrase, and that they must be allowed to institute idioms that do not yet exist.

- Jean-François Lyotard, The Differend: Phrases in Dispute 
$\mathrm{T}$ his article draws on aesthetics (Kantian and Lyotardian) and a distinction between topographical and topological markers to demonstrate a case for Paul Virilio as a rewriter of modernity based on Jean-François Lyotard's notion of "rewriting modernity" as a process of accumulation founded on affective life. ${ }^{1}$ In his article "Re-writing Modernity" (1987) and his philosophical essay "Argumentation and Presentation: The Foundation Crisis" (1989), Lyotard uses Kantian aesthetics (in particular the judgment on taste in Immanuel Kant's Critique of the Power of Judgment [2001]) to argue that technoscience and its logic of calculation have produced a foundation crisis in which forms of space and time (forms of givenness) have retreated and been replaced by formlessness, end goal, knowledge, and technical performance. Rather than a crisis of reason or cognitive discourse, Lyotard locates a foundation crisis in the loss of a community of feeling in the sublime. ${ }^{2}$ Central to his hypothesis is the idea that beneath what we call "reality," "something is first given. .. . There is, beyond the system, a more or less mute exteriority whose silence has to be lent a voice and that this is what it means to know" (Lyotard 1989: 120). Lyotard claims that the "something" that is "first given" comes before thought (akin to a "sensible" givenness) — that is, "outside" the sphere of argumentation and metapragmatics. How one accesses, registers, or records this givenness raises key questions for Lyotard in respect to receptivity (reflexivity), subjectivity, and ontology. Lyotard turns to two main ideas in Kant's aesthetics. The first is the presupposition of an "infancy of thought" in its "adult age": "It is in this way that critical aesthetics opens the path to ontology; the infancy it reveals is an approach and access to being" (126). ${ }^{3}$ The second idea is aesthetic feeling and what it means as a reflexivity. In feeling, reflexivity is felt to be "pure" - "that is to say, it is as close as possible to presentation before the 'mind' wishes to seize hold of the object and constitute itself over against it as a legislative subjectivity" (128). ${ }^{4}$ On this basis Lyotard establishes the key principle that feeling is not just the primordial mode of reception of any givenness but that subjectivity is revealed in aesthetic feeling and is not an already constituted subject who additionally experiences feeling.

Addressing receptivity and reflexivity in respect to shared feeling and subjectivity has profound implications for how we relate to the present, past, and (post)modernity. For Lyotard, one of the main implications of aesthetic feeling is that receptivity is not defined/located in a point of origin, place, fixed moment, or subjectivity but in space and time. And as such the "given" of feeling is the "immediate conversion of space-time into a mental state . . . ; the immediate transitivity of forms into feelings" (128-29). The spatiotemporal dimension of Lyotard's aesthetics as shared feeling (this is the crux of how he understands the foundation crisis) ${ }^{5}$ informs us how Lyotard proposes to address modernity as an unmediated, continuous "silent sharing" (133) that is not articulable in concepts but is feltpure and simple-through "an infancy of community, a trans-subjectivity prior to the constitution of individual subjects" (132). This aesthetic relates to my second methodological approach in this article to Virilio's work, namely, the textual distinction between topographical and topological markers. Le futurisme de I'instant (2009) ${ }^{6}$ is arguably one of Virilio's most outspoken critiques of globalization, human 
displacement, and digital and technological "révolutions" and their impact on the individual and daily life. With an emphasis on space (distance and proximity) as a metaphor of qualitative and conceptual thought, topography and topology can be applied to study how Virilio represents sociocultural and historical change. Topography is characterized as a discourse of compressed spatial dichotomies and fixed spatial times and geometries framed by a boxing ("freeze-framing") of historical displacement, itself underpinned by the stylistic effects of capitalization and italicization of key word ideas (mots-valises). Topography by extension reinforces a modernity founded on the elision of trajectory in favor of "squaring" history and horizon into fixed moments, origins, and objectified causes and concepts. Virilio's concept of the "squared horizon" can be viewed therefore as a spatial/textual metaphor for framing perspectives on time. Specifically, it reflects a topographical compression of time through the cult of the image as live transmission "that does not allow the present to pass away" (Virilio 2002: 22). In this "real time," duration, delay, and replayprocesses that enable thought, reflection, and analysis-are prohibited. As a result, Virilio claims that we are in the "grips of . . blurred perception" (23) that restricts perspective.

With a view to rereading this topographical representation of modernity, I draw on Lyotard's theories in "Re-writing Modernity" and aesthetics in "Argumentation and Presentation: The Foundation Crisis." Based on the idea that rewriting is part of writing - not a return to a point of origin or redefinition of the past but a "working through" of "projects, programs and prospects" (Lyotard 1987: 4) (including the present), I analyze the use of topology as resistance to topography's spatial/ conceptual shrinkage, including technological and urban transformation and a wider trend toward totalization over dynamics. Topology invites us to rethink space and time-and modernity_as a self-sustaining spatial and relational continuum where spaces exist ontologically and where immaterial forces of the dromospheric and the atmospheric generate a relational connectedness. Via an analysis of the elongation of space in Virilio (and by extension time and history, whose measurements are not condensed but are expanded by the unlimited "coordinates" of the ground, habitation, inertia, the sedentary, and the domiciliary), topology enables us to perform two key activities: first, to disassemble the vertical and fixed topographical structures of plier/replier (fold/fold down) and develop a topological semantics of resistance located in the unfolding (dépliage) into horizontal historical space through the language of aesthetics, free association, reflexivity, and memory. Second, topology's continuing relationality is reinforced in Lyotard's receptivity of modernity as an aesthetic feeling in which, crucially, shared feeling (sensus communis) forms the relational structure between space and time.

\section{Rewriting and Topology}

This is the world, the cultural world of our increasingly topological modernity. It is a world in which capital itself operates increasingly not through linearity of the symbolic and the commodity, but through the logic of the self-organising social imaginary and intellectual property. This is a world in which capital accumulates through the sort of individualisation that is constituted when Globen, when the topographical universal mind and topographical subjectivity, shatters into a million fragments like the exploding heads in 
David Cronenberg's Scanners. After which each of these heads in its capsule, in its individualised atmosphere is integrated in the now self-organising micro-units of capital.

—Scott Lash, "Deforming the Figure: Topology and the Social Imaginary"

Nearly ten years after the publication of The Postmodern Condition: A Report on Knowledge ([1979] 1984), 'Lyotard (1987: 8-9) wrote "Re-writing Modernity," in which he revisits the "provocative" nature of the former text, claiming that "postmodernity is not a new age, it is the re-writing of some features modernity had tried or pretended to gain, particularly in founding its legitimation upon the purpose of the general emancipation of mankind. But such a re-writing, [as has already been said], was for a long time active in modernity itself."8 Deconstructing the materialization of cultural history in terms of "pre-" and "post-," Lyotard also questions the position of the "now," the present vantage point from which we claim to have a right view over the successive periods of our history. ${ }^{9}$ Lyotard argues that postmodernity is implied/inherent in the modern age insofar as "modernity presupposes a compulsion to get out of itself and to resolve itself . . . into something else" (4). "Re-writing," he advocates, has two functions. First, it is a gesture that starts again, a beginning of something new. Second, it can also mean not going back to the origin at all but a "working through .... a work of thinking the meanings or events that are hidden not only in prejudices but also in projects, programs, prospects" (4). He confirms that there is no issue with naming or designating origins or facts in themselves (hidden or otherwise) at the origin of things but that it is in the problematic process of remembering "that we are driven to carry them on" (5). Origins and names, by implication, have the uncanny way of inscribing themselves into our historical memories, creating moments and events and places that stand out as unique and therefore remain invested with meaning. For Lyotard, this is a misrepresentation of the transitivity of the past, based on what he calls the fictive metaphysics of the "now." Lyotard views modernity in much the same light-as an unbroken continuum: "Rather than a genuine re-writing of modernity (i.e. from scratch), we are still performing the writing of modernity itself, that is because re-writing modernity is part of writing it. Modernity writes itself, inscribes itself on itself as a perpetual re-writing" (5). The broader significances of this second interpretation of rewriting are manifold. For Virilio and particularly his work Le futurisme de l'instant, they raise questions about how we read Virilio, as the "postmodern" who speaks in terms of "révolutions de l'esprit"; the posthistorical, of the abrupt end of one age and the beginning of another, whose capitalizations, italicizations, and "word-bites" seek to reset "the hands of the clock at zero" (4); or as the "modern," for whom the modern discourse of transmission, transitivity, and transsubjectivity flattens the postmodern squaring of historical displacement. Lyotard's theory of rewriting modernity, alongside his philosophical essay on Kantian aesthetics, will underpin the topological study of modernity I undertake in this article.

Topology is a method of analysis that exposes mathematics to a nonmetric and nondiscrete articulation of experience. It has gained considerable currency in recent cultural and social theories as a way of mapping movement in space (Sloterdijk 1998, 1999, 2004; Lash 2012; Lury et al. 2012). "We no longer live or experience movement or transformation as the 
transmission of fixed forms in space or time, but rather movement-as the ordering of continuity-composes the forms of social and cultural life themselves" (Lury et al. 2012: 6). In other words, topology emphasizes the process of continuity for an understanding of the principle of relationality as the production space of alternative forms of discourse and organization. The theorem of the continuum therefore is critical to topological thinking. It means that instead of thinking of the relational space between two points as discrete set points, we think of the continuum as the space of relation as differential that exceeds the entities it relates in the direction of the infinitesimal. In this way the relation is not defined by finite points of determination or integration but is determined elsewhere, where these points are part of a field of changes, tendencies, and vectors (de Landa 1991). Penelope Harvey (2012) and Scott Lash (2012) have expanded the use of topology as idiom and semantics and crucially as a binary that includes what they call "the topographical." "The idiom of the topological offers a language for articulating the continuity and relationality of modernity in contradistinction to the topographical or discrete/ set idioms deployed to conjure more static notions of space" (Harvey 2012: 77). Lash explores the binary in even more detail. He writes that topographical space is form in space. It is the horizon where subjectivity and meaning are defined. It is also, he claims, the outside where death, the end, and finitude exist, and it is extensive accumulation over time. Topological space, by contrast, is "anti-form, de-formation, not located in space, but rather it is space itself. Rather than horizons of meaning and subjectivity, topological space gives us atmospheres, physical spaces, intensive accumulation, it is the horizon ... . shattered into an infinity of atmospheres, in which we constitute fragile and plural meanings" (Lash 2012: 270).

Lyotard sees in the process of rewriting a way for modernity as connectedness and continuity to not only self-sustain but also resist demarcation and disruption through processes of immanence, production, affect, aesthetic pleasure, and intense accumulations. Following Lyotard's "re-writing" and building on Harvey and Lash and the "idiom" of topology, my aim is to develop a topological semantics of resistance to the topographical in the writing of Virilio and particularly in his work Le futurisme de I'instant. I argue the case for Virilio as a rewriter of modernity in the way his "writing" on one level reflects a tendency to totalize and universalize through the use of metanarratives but as a process of "re-writing" can be read as a form of aesthetic resistance to the topographical "boxing," "squaring," and "prefixing" practices of postmodernity that privilege systems, forms, and structures as well as attempts to speak and delineate in terms of origins, whether place, identity, or the "new ecologies of time" (Lyotard 1987: 3). In Virilio's rewriting modernity we see that what topography orders and systematizes from the "outside" (as horizons-including revolutions, technology, digitalization, Italian futurism), topology generates and causes from the "inside" (as space) (Lash 2012: 271). Topological spaces in Virilio (the ground, the sky, the sedentary, the domiciliary, habitation, and the inert) are invested with aesthetic feeling, a shared feeling of transitivity from which the "subject," far from a fully constituted subject who absorbs experience independently and inwardly, permeates a collectivity of feeling (sensus communis) that is universal, timeless, and continuous: 
What is at play in aesthetics is not an already constituted subject that would, additionally, be experiencing a feeling but rather a redescent, a catamnesis towards that on which the constitution of the subject, in its heterogeneous faculties, is supported. It is a "mother-layer" of the facultary powers and their unification in an "I" that is revealed in the aesthetic feeling. ... Receptivity of feeling is not "internal" to the subject; it is, rather, an archaic destiny toward the other, a permeability. The subject as ensemble (an ensemble that, we may say in passing, is always fragile) of active appropriations of the given. (Lyotard 1989: 128-29)

In topology therefore spaces do the existing (Sloterdijk 1998, 1999, 2004) in the same way that aesthetic feeling opens the path to ontology (Lyotard 1989: 126). What is significant in this is that spacetime, where the architecture of subjectivity is deconstructed, becomes the new "mental state" in which modernity unfolds of its own accord. In the absence of any "destinateur" and "destinataire" (128-29) that structures the subjective computation and transmission of feelings, Lyotard alters the way we access the past. Feeling is not an emotion controlled or experienced by a subjectivity located in the "now," nor is it an emotion that a subjectivity "experiences" in a recuperative way either "after" or as an effect of nostalgia. Reception of the past, rather, is an immediate feeling, the "immediate conversion of space-time into a mental state" (128-29): "a pure feeling before it becomes the schematic registration of data that can be processed with concepts. We may say that aesthetics take place 'before' the subject/object division to such an extent that it is problematical to attribute the feeling of beauty to a subject" (128). Aesthetic feeling is "merely" felt (128). Rather than extensive accumulation over time, aesthetic feeling is intensive accumulation "in which we constitute fragile and plural meanings" (Lash 2012: 270). The Virilio scholar Ian James raises an important note of caution in this regard. He claims that there is a danger in seeing these "absent" spaces of topological modernity ("sol," "ciel," and the inert) in terms of a facile opposition between a nostalgia for a lost time and space (nostalgia as another "horizon" onto the past) and an originary presence or self-identity that can be recuperated. He states:

There is no homely origin of a seeing body in Virilio; if teletopological technologies can have such a powerful impact on the "map of what I can do" that is because that map has already and from the beginning been charted out in an imaginary technicity of bodily life. . . . [Virilio] should not be aligned with a conservative cultural agenda that yearns for the restoration of a lost presence or the recuperation of the capacities of the "body proper." He needs to be aligned much more with contemporary thinkers such as Stiegler whose deconstruction of phenomenology via a thinking of technical prosthetics is carried out in the name of a struggle to liberate our culture from the levelling and deadening effects of mass consumption. (James 2013: 239)

In the same way that Lyotard eschews feeling as subjective experience and as nostalgia for a lost time, James locates the "struggle" of feeling in Virilio in the very production of the visual. In the absence of a mythic "originary presence" he finds "an originary dynamism of production, an originary transformability or plasticity of presentation" (233; italics added) that is activated at the point of visual contact. For James, dynamic transformability captures the immediacy of our reception of visual production. James is quick to dispel conservative tendencies in Virilio to 
articulate time and space in respect to the suppression of immediacy and instantaneity and the values shaped by grounded bodily experience. But in doing so James also identifies a key feature of topological modernity in Virilio and signals the direction of this article: modernity as continuum through dynamic differential relationality. For James, these absent originary spaces in Virilio have, as he says, "always already" been inhabited by technicity, "that map," he says, "has already and from the beginning been charted" (239). As with Lyotard's theory of "re-writing" - "writing that has been written, not a start from scratch but a continuum where the past is still presenting itself and not re-presented"topological modernity in Virilio is underpinned by a dynamic self-vitalization of relationality and space: "He who dreaded that the sky would fall, he who feared the liquid mass and movements of the ocean, tore apart a logical structure of vital importance, an essential continuity between the solid and the liquid, between the gaseous and the mineral, between presence and absence: he destroyed the relationality of the instant of vision" (Virilio 2005: 38; italics added).

\section{From Topography to Topology}

Harvey (2012: 77) writes: "Topographical idioms mobilise co-ordinates and metrics of fixed spatial times and geometries ... giving singular and absolute depictions of the space in question. Topological idioms draw attention to spatial figures where insides, outsides, edges, borders, intervals are continuous (not demarcated) and where it is the mutable quality of relations that determines distance and proximity, rather than a singular and absolute measure." Prefixes, capitalizations, and italicizations are critical topographical and topological markers in the Virilian text (these markers are often and regrettably overlooked in the English translation). Topographically, they frame the periodization of time, place, and event and nominalize processes and practices associated with historical displacement and sociocultural change. The prefix and the proliferation of prefixes (EX-, ÉCO-, OUTRE-, SUB-, DÉ-, GÉ-, GÉO-, BIO-) qualify and extend multiple trajectories. When deployed, as they often are, in pairs or binaries, prefixes can have the effect of reterritorializing time and space, totalizing and stagnating process into generalized, ill-defined block ideas in the fashion of the squared horizon. Rather than extending chronology, the prefix annexes the nanochronologies it purports to unearth: "De fait, nous assistons là, au début de ce troisième millénaire, à l'expérience d'une forme absolument inconnue d'exterritorilaisation du potentiel humain susceptible d'interdire bientôt toute possibilité d'un quelconque potentiel urbain, qui déboucherait, cette fois, sur une forme nouvelle d'EX-CENTRICITÉ, où la quête d'une EXO-PLANĖTE, d'un OUTREMONDE de substitution à l'ancien trop pollué, se déboucherait, ici-bas, de celle de I'OUTRE-VILLE, sorte de plateforme logistique dont l'aéroport, le port et la gare n'étaient jamais que des modèles réduits" (Virilio 2009: 14-15). ${ }^{10}$ Conversely, however, one could argue that the prefix creates a series of new relationalities, extending the nominal to new limits—connecting the local and the natural, the personal and the social, the "bio-" and the "eco-." In this sense the prefix extends beyond its status as topographical marker to assume topological significance as a "sociotechnical field of abstraction in which the possibility of new relations between ontology and epistemology are emerging" (Lury et al. 2012: 20). The prefix, akin to the theory of the "border as method" (Mezzadra 
and Neilson 2012) and Lash's (2012) notion of the "spatial figure," has the potential to transform space relationally. For Sandro Mezzadra and Brett Neilson (2012: 64), the "border as method" is not synonymous with a return to the nation-state on the world stage but is border as "a strategic angle on actually existing global processes." It is my view that in Virilio the prefix and its uses are part of a transformation of word and cognitive borders, the aim of which is to "manage the creative destruction" and "constant recombination of spaces and times" that shape capitalist globalization (64). The prefix therefore is a flexible space of undoing and redoing, reflecting the idea of the "fundamental flexibility of contemporary borders and of territories they are meant to circumscribe" (65). However, what is significant about its topological use in the context of Virilio as a rewriter of modernity is the way the diversity of prefixes brings together not only a diversity of knowledges but also a different means of knowledge production, underlining the fact that "geographical and cognitive borders and distance do not actually separate different practices and experiences" (65) but are part of a wider relational continuum that is modernity.

We can advance the same argument vis-à-vis the widespread use of capitalizations and italicizations in this work and more generally in Virilio's writing. The following is an example: "Une accéleration de I'Histoire qui débouche non seulement sur l'épuisement de la GÉO-DIVERSITÉ du visible, mais aussi sur l'extinction progressive de la CHRONO-DIVERSITÉ du sensible" (Virilio 2009: 95)..$^{11}$ This typical formulation, of which there are many, deploys prefixes and capitals as discrete units of spatiotemporality. Susan Sontag $(1977,2004)$ has referred to this process as the "freeze-framing" of historical displacement. Topography captures the reduction of time, space, and thought into abstract capitalizations that designate and design their own "real time. ... A practical durée that permits no reflection" (Virilio 2002: 24). In this way topography writes modernity as a "squared horizon," caught in presentation in real time (23). Topography captures in reduced form the speed of change and the way digital technology, displacement, and globalization have compacted history, including semantic syntax, into what Virilio calls the "POSTHISTORIQUE" "contenuerisation" (containerization) of cultural production (47). The topographical curation of space on a typical Virilian page in Le futurisme de l'instant is framed in an antithetical system of word composites (HABITATION/INHABITATION, COSMOPOLIS/CLAUSTROPOLIS, GÉNOCIDE/GÉOCIDE), each word/prefix in a pair conceptualizing and materializing as discrete spatial entities the past, present, and future as well as cultural change. ${ }^{12}$

Topology, however, invites us to break from the topography of the "squared horizon." Between the composite blocks and interposed images, the immaterial forces of the atmospheric and the dromospheric flow in dynamic spaces like train, bike, and taxi rides-where the human/physical sensation with space in motion generates a particular connectedness, what Xin Wei Sha (2012: 222) refers to in topology as the concept of continuity "corresponding to the quality of lived experience." For Virilio, these spaces are often inset in italicized form or placed into special relief in inverted commas ("véhicules dynamiques," "locomobilité," "automobilité," "surfaces orientées," "serre atmosphérique"), all resonating with the human potential and aesthetic feeling that Virilio implies still exist in these spaces and that serve to arrest technological change or alter its 
desensitizing course. The atmo-sphere and the dromo-sphere are the topological spaces in which Peter Sloterdijk (1998, 1999, 2004) claims new meanings are taking shape in the globes, the spheres, and the foam of processes not only in networks of technosocial transindividuation but also in and on the surfaces and edges of things in our life experiences (intimate spaces, walls, roofs, floors, grass), ${ }^{13}$ in the destruction of unitariness, and in the mutable intersecting of relational space. As I argued earlier in the context of the prefix as a topological space of modernity with ideological, productive, and transformative capacities, "communication" not only happens as a relationality in a continuum, but critically communication is nonconceptual. In "Argumentation and Presentation" Lyotard reminds us that communication of feeling is different from "communicational competence." Feelings are communicable in the way they invoke "a kind of community via the sensus communis (understood in the sense of a shared sensibility)" (Milne 2013: 111). It is in this shared feeling that the "subject" as "infant" is born, not in the communicational competence of adulthood. Topology reinforces relationality as communicable feeling. Lash states that communication does not take place in isolated topographical or topological spaces. It happens between topological spaces-"between the atmospheres of isolated individuation" (Lash 2012: 270). Virilio's atmo-spheres are spaces charged with aesthetic feeling that do the communicating via the enduring processes of "durabilité," "habitation," "matière vivante de l'humanité." The communicative connectedness between relationalities "does not simply happen IN the in-between but rather operates a topological continuum OF the in-between" (Lury et al. 2012: 13). As aforementioned, we can read the topographies of the prefixes and capitalization as parodies of modernity's continuum. But I would argue that this would be to overlook a more sustained and subtle critique of technological and urban progress in which topological modernity is not the object of satire but a force of resistance.

\section{Topology as "Re-writing"}

My hypothesis where postmodernity is concerned is that aesthetics - that is to say, the openness to the givenness of the Other according to spatial and temporal forms - which constitutes the foundation of critical and Romantic modernity, finds itself repulsed, weakened and forced into resistance on account of the hegemony of the technoscientific and pragmatic seizures of space-time.

—Jean-François Lyotard, "Argumentation and Presentation: The Foundation Crisis"

We have seen how Virilio is not often given to historical exegesis (Matthewman 2013), and certainly not in this work under current study. His writing style is more hyperbolic, at times slapdash. There are, however, moments in Le futurisme de l'instant when, for example, Virilio looks to account for the origins of his idea of the "outreville" (ultracity). In a break from standard practice, he describes how the "outreville" is born out of the geopolitical insecurities of territory (warring nations, the creation of bombardments, new railway lines, city limits redrawn as a result of inner-city destruction/blitzes, etc.). More often than not, this brief escape into relational topological modernity is aborted by a return to history as the polarized prefixing of “GÉOPOLITIQUE" versus "MÉTÉOPOLITIQUE" (Virilio 2009: 58). But what is noteworthy here is the way Virilio rewrites modernity as a continuum from inside the politics of the topographical, deploying the prefix to redraft spherically the idiom of 
modernity. In doing this Virilio shifts the semantics of political discourse from the polarizing power of the political economy to the co-ordinates of atmospheric interactivity. Alternative routes of "communication" (aesthetic and symbolic) are subsequently opened. Echoing his claim in Desert Screen that resistance is an act of political philosophy with serious if not fatal consequences, I would suggest that in these examples Virilio $(2002: 24,27)$ is rewriting a space for a realignment of topological modernity as an act of political ideology and philosophical resistance. The final lines of Lyotard's (1987: 19) "Re-writing Modernity" read: "The question raised by those New Technologies with regard to the idea of rewriting as it has been sketched out could, therefore, be shaped like this: what is left of the working through, between a before, an after and a now? How can it [rewriting] escape from the rules of concepts and recognition? For the time being, my answer is limited to this: to re-write modernity is to resist the supposedly postmodern writing." Rewriting resistance takes multiple forms. It is evident, paradoxically, in what appears to be a language of compliance. Virilio's stylistic compressions can convey the impression not only that technoscientific change has happened too rapidly but also that it has met little or no resistance. Consider, for example, the same types of connecting verbs Virilio uses to link the processes of cultural change: "céder place à" (give way to), "donner lieu à" (give rise to), "en voie à" (in the process of), "supplanter par" (supplanted by), "déboucher sur" (to come out onto), "remplacer par" (replaced by), "emporter par" (carried away by). These are not the topographical markers of cultural change founded in the language of negotiated consensus or developmental progression, nor is it the language of transmission, transitivity, or continuum. On closer inspection, these verbs are premised semantically on an a priori position of acquiescence, on something giving way, on letting go of something. My argument is that inside this semantics of passivity Virilio identifies a topology of resistance, resistance in the relationality of the verbal conjunction deployed but specifically resistance residing in the topological space of the prefix ("sup-planter," "rem-placer," "em-porter," "dé-boucher"). In the spaces of these prefixes, the ownership and direction of the historical is shaped. It is my view that what appears as a space of invariant subordination is in fact a productive topological space to resist by whatever means possible the "squared horizon" and its logistics of blurred perception. The prefix emerges again as the space to rewrite the "propaganda of progress" (the term used by the French publishing house Galilée to market this book).

Inertia (domiciliary, sedentary, stationary), as the resistance of any object to a change in its state of motion, reinforces the durability of modernity and its means of transmission. Living matter (the body and the "habitable" spaces and controllable movements, like bike, car, taxi rides, as opposed to the polar inertia of the plane, the ship, and the rocket) resists the pull from the "sol" (ground) to its prefixed opposite "hors-sol" (off the ground) and its attempts to "géo-localiser" (geolocate). There is a trend here toward establishing points of topographical origin-including material-that in themselves assume the significance of an originary presence that periodizes references and produces (dis)(re)continuation. Lyotard forewarns of this tendency in the process of rewriting. "Lost time," he says, "is not re-presented on a tableau or even presented at all. Lost time is presenting the elements of 
the tableau and re-writing is primarily the recording of them" (Lyotard 1987: 7). For Lyotard, rewriting does not result in a "definition of the past." Rather, "it presupposes that the past is acting by giving the mind the elements with which the past is built" (7). This leads Lyotard to conclude that in rewriting you do not arrive at an exact copy of what he calls the "primal scene"; instead, the past becomes new, because it is felt to be new. He notes: "I would say that it [the past] is not present as an object, if an object can be present at all, but as an aura, a mild wind blowing" (7-8). James (2013: 228) identifies a similar process at work in Virilio: "This [the visual] is not a struggle waged in the name of recuperation of a plenitude or immediacy of presence and against the empty virtuality of a denatured experience. Throughout the opening pages of Negative Horizon . . . it is far more a question of a hierarchy of vision that imposes preformed structures of perceptions and, against these, the attempt to seek out and reveal the in-between, the marginal, the concealed, the new and the different." It is fair to suggest therefore that the idea of an original "sol"/"polis" in Virilio is in fact without foundation. It is irretrievable as an object and as a totality. However, as I have maintained via the use of topology and as James confirms in the context of the visual, the logic of this fixed past gives way to ("cède place à") its potential to "act" and "becomes new." Topological modernity in Virilio writes itself into and against late modernity, because we readers feel it as an intense accumulation of transcendent shared feeling. Echoing Aristotle's hexis, Walter Benjamin's "aura" of history, and Pierre Bourdieu's "habitus" of nondiscursive knowledge that "goes without saying" and including the insistence of Virilio's inert "inhabitation," modernity is seen to persist as resistance in Virilio's imagination/writing through the "technicity, technical prostheses and objects" (239) invested in the domiciliary, the sedentary, and other states of permanence.

Rewriting modernity, Lyotard underlines, is a process of "working through," a working through of meanings and events that have been hidden by origins, history, objectifications of first causes, or the setting of things apart, in isolation. It is also a working through of memory, acknowledging the need to remember but without purpose or aim and remembering as an act of floating association in which everything remembered has its place. ${ }^{14}$ Lyotard (1987: 7) writes: "[Free association] is nothing but a way of linking a sentence with another without regard for either the logical or the ethical or even the aesthetic value of the linkage." Lyotard repeals topographical modernity as material periodization and instead unfurls it as a continuous work in progress, a continuity of relational differentiality made up of disparate accumulations of elements and debris (Benjamin 2003). ${ }^{15}$ Virilio's topologies of space lend themselves to this rewriting of modernity, and none more so than in the three spatial metaphors used in the context of the "outre-ville"-all topological variations on the word plier (fold), including "re-plier" (fold down, over) and "dé-plier" (unfold) each capturing the processes of working through modernity. Folding and unfolding spaces represent competing urban trajectories of the "outre-ville." The verticalization of space associated with topographical modernity is caught in the word replier, whether it be in the image of the collapse of urban space into a folding umbrella or in the "perpendicularité ascensionnelle" (rising perpendicularity) of contemporary city dwelling. ${ }^{16}$

In this image of folding down and 
around ("re-plier"), in which horizontal space is compressed, lies a metaphor for what Lyotard (1987: 3-4) calls the "principle of the vertical," defined as a new "fake reality," a "meta-physics," a putting down (or writing down) in the sense of a historical recording or inscription. Virilio's broad thesis across his later work is to discredit forms of "ex-territorialization" and digitalization and their impact on our sensory perceptions. But I would suggest that he also seeks to undermine them spatially as historical ruptures in topological modernity. For Virilio, these vertical "histories" interrupt the logic of free association (the "emporium" effect, as he calls it) by designating the "now" of late modernity as a discrete unit of time with differential value and power (the "imperium" effect). By way of response, the rise of the "outre-ville" skyward is also a spatial and symbolic rupture that Virilio reframes in horizontal space and as a function of modernity as a dynamic continuum. The verb déplier (to unfold), not forgetting the prefix, rewrites this modernity as it unfolds: "II manque un troisième et dernier terme pour désigner cette pratique dynamique de la résidence de l'humanité, c'est celui de DÉPLIER l'espace topologique de la cité, au lieu de le hérisser de tours plus hautes les unes que les autres dans un principe vertical d'orthogonalité, hérité d'un style néogothique" (Virilio 2009: 54)..17

One of the "pre"-requisites of modernity as free association or emporium is human engagement (the "topology of lived experience," as Lash [2012] claims, or "feelings ... as a region of resistance," in the terminology of Lyotard [quoted in Milne 2013: 111]). Aesthetic feeling, like memory without purpose, is the alternative guarantor of modernity's continuum. Unlike technoscience that seeks to submit all givens to the logic of calculation, feeling starts from a point prior to conceptual logic..$^{18}$ Feeling resists this logic by attesting to what Lyotard calls a primordial moment of "showing" of sensory data. For Lyotard (1989: 131), "listening to" feelings in particular carries special significance. Listening reinforces the human encounter that feelings engender as "joint participation" in how we think and process modernity as sensus communis. Aesthetic feeling as sensus communis renders obsolete the single perspective on memory from any one specific vantage point. On the contrary, it opens memory to the permeability of multiple perspectives that "deform" positively the architecture of memory. ${ }^{19}$ Both Lyotard and Virilio concur on this idea of memory as a continuous layering. ${ }^{20}$ "Your only certitude," writes Lyotard (1987: 7), "is that it [memory] refers to the past-both the farthest and the nearest past; your own past and the others' too." Virilio (2005: 37) writes, "Today we are no longer truly seers of our world, but already merely reviewers, the tautological repetition of the same, at work in our mode of production . . . is equally at work in our mode of perception." What Virilio is saying in effect is that visual culture, and I would claim modernity, is a process of unfolding immanence, and rewriting/reviewing it, listening to feelings as technique in the production of immanence, best captures the element of free association in modernity-not rewriting or reviewing as a retrospective recognition or new renewal but rewriting as a means through which modernity presents itself unsolicited and as an act of repeating continuity. Rewriting in this way reconfirms the death of modernity as author and metanarrative and replaces them with us scripters in its creation. 


\section{Conclusion}

Topological and topographical markers are the "differends" that shape the expansion of the Virilian "outre-ville." They frame the debate in respect to how Virilio views this expansion as a conflict of spatiotemporal, geopolitical trajectories but also critically as a form of resistance. Lyotard's rewriting modernity-underpinned by an aesthetics of the sublime and a theory of the inhuman-brings this resistance closer into textual and discursive relief. For Lyotard and to a point Virilio too, we must become inhuman to be human — that is, relinquish our hold on the metaphysical, lose our grip on the chronology of developmental time to gain the time of the past, lose time to win time to access the sublime sentiment of feeling as emotion and sensus communis. The inhuman therefore resists the human in a positive way. ${ }^{21}$ I have proposed in this article that we can read Virilio in Le futurisme de l'instant as a writer who is rewriting modernity primarily through forms of resistance: resistance via a semantics of topology that includes the idiom of the prefix and atmosphere as enduring spaces of habitation; resistance through a style and language whose radical brevity and conceptual compression draw attention to the elision of historical time and space and the reductive impact of electromagnetic technological progress on processes, practices, and techniques; resistance through the hidden energy of inertia, the draw of the ground, living matter, habitation, and movement that resist the pull of the "hors-sol"; resistance through space, the rise of vertical space at the expense of horizontal space in the "outre-ville" and the symbolic nature of this spatial differentiation, and the resistance implied in topological "dépliage" for an end to modernity as rupture and its return as dynamic continuum; and finally, resistance through aesthetic feeling. Feeling as sensus communis, as a technique of collective resistance in writing about what Virilio sees as being threatened and forgotten (belonging, a lifeworld, civic society, community and social links, the ground giving way to the sky). Virilio is in fact rewriting these "losses," pulling together these "leading threads in the working through of modernity" (Lyotard 1987: 7), keeping them present, reinscribing them in our consciousness, never letting them go, asking us to rewrite our own nanochronologies. He wants us to resist the onset of the culture of the "now."

\section{Notes}

1. Steve Redhead is another cultural and social theorist who has turned to the work of Virilio in the context of "critical modernity." Claude Parent is associated with the term critical modernity, although Virilio, through his links with Parent, acknowledged its social and affective impact (Lotringer and Virilio 2002: 8-17). In Redhead's (2005: 19) definition of the term, there are remarkable overlaps with Lyotard's idea of "re-writing": "Critical modernity is always already within the modern. Critical modernity demands relentless reviewing of processes and methods, and continual reinvention of vocabulary. It is to practice a positive questioning of modernism from within and to protest against the industrialization and mass construction inherited from an earlier era of Modernism."

2. Behind Lyotard's theory of rewriting modernity is the question of the sublime (Slade 2007)—finding a mode of presentation for the unpresentable of thought. In his work The Differend (1988) Lyotard develops the idea of the difference between knowing and feeling in his aesthetics of the sublime; knowledge and metaphysics being secondary to the violence of feeling, the failure of thought being the source of the sublime sentiment. If the differend therefore is that state of the unpresentable (the condition of being dispossessed of language), Lyotard invokes a number of "idioms" to bear witness 
to this "loss." Reflective judgment (rather than critical judgment) is one way he forces thought to look at ways of making the unpresentable come into language and address the differend. "Idioms" generally — in their textual, filmic, plastic, and (I argue) spatial figurations - provide ways of bearing witness to events of the past and our own pasts. Rewriting, as this article demonstrates, is another of these "idioms."

3. Andrew Slade (2007: 52) states: "We are constituted by our childhood, owe an irreparable debt to that childhood. Childhood becomes the object of anamnesis that seeks to open possibilities for human action and thought beyond the repetition of the tragic, classical stories."

4. Reproduction or representation offers no critical hold on events: "Sublime presentation through plastic or verbal images lessened the terror of presentation together with a promise of continuity" (Slade 2007: 14-15). Presentation seeks idioms to articulate the impossible, the unpresentable, but as Lyotard suggests, as a function of thinking, presentation is also limited.

5. "I see in this an anticipation of the true foundation crisis, afflicting not reason but space and time as forms in which the Other is present" (Lyotard 1989: 127).

6. All references to this specific work are in French. The French original is central to the textual analysis I undertake in this article.

7. Lyotard is not the only theorist in recent times to rethink modernity and postmodernity (Bauman and Tester 2001; Beck and Willms 2004; Giddens and Pierson 1998). However, in the context of this article, some of the more relevant "rethinking" has been taking place in the field of architecture (Bideau 2002). In the editor's introduction to the special issue on Claude Parent, André Bideau (2002) examines the "spatial turn" in architecture and urban discourse against the concept of postmodernity.

8. Invoking Virilio's contemporary in the 1950s and 1960s, the architect Parent, Redhead outlines a different approach to the opposition (modernity/postmodernity) to Lyotard's theory of "re-writing" modernity and to our discussion on topological modernity in which the "spatial turn" and "spatial syntax" are implicitly acknowledged.
Redhead (2005: 52) writes: "The problem in such theorization remains the binaries created which are in need of deconstruction: modernity/ postmodernity, modernity/late modernity, solid/ liquid modernity, first/second modernity. ...

The alternative idea of theorizing contemporary modernities, overlapping and competing, is appealing and can avoid the debilitating problem of periodization of the binary divides."

9. We may also wish to think of the "now" in terms of "presence" and "trace" (Derrida 1997) but also as the age of the metapragmatic that Lyotard speaks of in reference to technoscience in "Argumentation and Presentation."

10. "Actually, what we are now seeing, as the third millennium gets under way, is the emergence of an absolutely unknown form of ex-territorialization of human potential that is soon likely to rule out all possibility of any kind of urban potential. This will lead to a new form of eccentricity, whereby the quest for an exoplanet, an ultraworld, as a replacement for the old one, now too polluted, will double up, here below, with the quest for an ultracity, a sort of logistical platform - something which the airport, the port and the railway station have only ever been scaled-down models of" (Virilio 2010: 6).

11. "For want of an improbable end of history, this would have to be a sign of the imminent extinction, not of the human race, certainly of the chronodiversity of sentient life" (Virilio 2010: 101).

12. Steve Matthewman writes on the stylistic trend in Virilio toward "suggestion" over "qualification" with the implication that Virilio is less interested in the detail of empirical elaboration. Matthewman (2013) refers to this as "grand theorizing" about general conditions that do not exist.

13. Patrick Keiller's film London (1994) is an excellent visual example of how the camera lens lingers on life's daily bricolage, using urban spaces to evoke the plasticity of aesthetic feeling.

14. The relevance of Lyotard's work The Inhuman: Reflections on Time (1992) lies in its critique of modernity from the twin perspectives of the (in)human and time and how this critique sustains the processes of rewriting and memory as "working through." Subverting the 
privilege afforded the rational human subject in modernity, the inhuman advances the thesis of antimetaphysics through a critique of the idea of "development" (through time) as the systematic expansion of capital as a logic that permeates social life. The inhuman (or antimetaphysical) is hostile to this developmental thinking and its progressive ideology. Rewriting is a way of testifying "to inhumanity as the resistant core of that, that secret which inhabits us and cannot be incorporated into the system" (Slade 2007: 40). Memory too is a blind alley if pursued as nostalgia or an attempt to undo the past. Instead, memory for Lyotard (1992: 15) is a "working through" in rewriting: "Contrary to remembering, working through would be defined as a work without end and therefore without will; without end in the sense it is not guided by the concept of an end-but not without finality." Besides the interminability expressed here, what is significant in this "working through" of memory is that we are listening to a feeling with the aim of attaining not a knowledge of reality but instead an "awareness" of a feeling being felt in nontime and nonspace: "Working through as re-writing is a technical process that aims to bear witness to a past that is both personal and shared, that is neither comprehended nor well described. ... Re-writing is a not a synthesis of sensible material and a concept or concepts. Re-writing is the procedure, manner, or even art that takes us to the source of the sentiment" (Slade 2007: 44; see also Houston Jones 2011).

15. Benjamin's "Angel of History" (based on Paul Klee's Angelus Novus [1920]) is an interesting metaphor in the contexts of topography and topology. The Angel views history (modernity) as a vertical space, debris piling up on debris. The Angel has no perspective on this vertical accumulation of the past other than its growing verticalization. In effect the Angel is unable to do anything about this (unable to make sense of verticalized accumulation and unable to make things "whole" in the sense afforded by perspective). The Angel is swept up impotently into the future-an impotence that Benjamin views as indicative of the inevitability of progress. Topography, defined as a historical fixed point and a point of origin in and of itself, by implication enables us to make sense of history and modernity in an isolated and discontinuous way. History and modernity in this topographical space are thus reduced to the repetition of the same single "catastrophe" over and over again (Benjamin 2006). By contrast, Benjamin offers "us" earthly humans, endowed with feelings (as opposed to the impotence of the Angel), a chink of insight into the chain of events that appears before us. This historical "chain"—whose links are revealed only to "us" (potentially via the human capacity for aesthetic feeling) — signals a topology of relationality that connects historical modernity in its differentiality.

16. The negation of the vertical has its roots in Virilio's spatial dynamic architecture, the function of the oblique and his work on the architecture of the bunker. Redhead (2005: 51) claims that the "vocabulary of the bunker was intended to create a repellent architecture that would overrun the established perception and provoke a response." For more on the theory of the oblique and the relationship between Virilio and Parent, please see Redhead 2005.

17. "We need a third and final term to refer to this dynamic exercise in housing humanity. That term is 'unbending' - unbending the topological space of the city, instead of causing that space to bristle with towers, each one higher than the last, based on the model of the orthogon that is the legacy of 'neogothic' style" (Virilio 2010: 52). I have used the word unfolding to convey this process.

18. In his work The Nearness of Others: Searching for Tact and Contact in the Age of HIVDavid Caron (2014: 64) states: "Affect pertains to simultaneity; it erases the gap between me and the world, the present and the past, giving me the impression that I am what I'm feeling. Reason is clean, affect murky."

19. In his novels The Emigrants (1996) and Austerlitz (2001) W. G. Sebald draws a distinction between official memory (exemplified in obituaries) and memory to which others' memories and testaments are added in the construction of the architecture of memory made up of multiple parts and voices that challenge the hegemony of single perspective memory.

20. Lyotard (1989: 128-29) uses this terminology 
also in the context of aesthetic feeling and subjectivity: "It follows that what is in play [in aesthetics] is not an already constituted subject that would, additionally, be experiencing a feeling but rather a redescent, a catamnesis toward that on which the constitution of the subject, in its heterogeneous faculties, is supported. It is a 'mother-layer' of the facultary powers and their unification."

21. Lyotard explores the dialectic between inhuman and human in The Differend: Phrases in Dispute (1988).

\section{References}

Bauman, Zygmunt, and Keith Tester. 2001. Conversations with Zygmunt Bauman. Cambridge: Polity.

Beck, Ulrich, and Johannes Willms. 2004.

Conversations with Ulrich Beck. Cambridge: Polity.

Benjamin, Walter. 2006. "On the Concept of History." In Walter Benjamin: Selected Writings, vol. 4, 1938-1940, edited by Howard Eiland and Michael W. Jennings, 389-400. Cambridge, MA: Harvard University Press.

Bideau, André. 2002. "Editorial." In "Claude Parent und die Folgen," special issue, Werk, Bauen, und Wohnen 89 (11): 3

Caron, David. 2014. The Nearness of Others: Searching for Tact and Contact in the Age of HIV. Minneapolis: University of Minnesota Press.

de Landa, Manuel. 1991. War in the Age of Intelligent Machines. New York: Zone Books.

Derrida, Jacques. 1997. Of Grammatology. Baltimore: Johns Hopkins University Press.

Giddens, Anthony, and Christopher Pierson. 1998. Conversations with Anthony Giddens: Making Sense of Modernity. Cambridge: Polity.

Harvey, Penelope. 2012. "The Topological Quality of Infrastructural Relation: An Ethnographic Approach." In "Topologies of Culture," edited by Celia Lury, Luciana Parisi, and Tiziana Terranova. Special issue, Theory, Culture, and Society 29 (4-5): 76-92.

Houston Jones, David. 2011. Samuel Beckett and Testimony. Houndmills, UK: Palgrave Macmillan. James, Ian. 2013. "The Production of the Present." In Virilio and Visual Culture, edited by John Armitage and Ryan Bishop, 227-41. Edinburgh: Edinburgh University Press.
Kant, Immanuel. 2001. The Critique of the Power of Judgment. Cambridge: Cambridge University Press.

Lash, Scott. 2012. "Deforming the Figure: Topology and the Social Imaginary." In "Topologies of Culture," edited by Celia Lury, Luciana Parisi, and Tiziana Terranova. Special issue, Theory, Culture, and Society 29 (4-5): 261-87.

Lotringer, Sylvère, and Paul Virilio. 2002. Crepuscular Dawn. New York: Semiotext(e).

Lury, Celia, Luciana Parisi, and Tiziana Terranova. 2012. "Introduction: The Becoming Topological of Culture." In "Topologies of Culture," edited by Celia Lury, Luciana Parisi, and Tiziana Terranova. Special issue, Theory, Culture, and Society 29 (4-5): 3-35.

Lyotard, Jean-François. (1979) 1984. The Postmodern Condition: A Report on Knowledge. Translated by Geoffrey Bennington and Brain Massumi. Minneapolis: University of Minnesota Press. Lyotard, Jean-François. 1987. "Re-writing Modernity." SubStance 16 (3): 3-19.

Lyotard, Jean-François. 1988. The Differend: Phrases in Dispute. Translated by Georges van der Abeele. Minneapolis: University of Minnesota Press. Lyotard, Jean-François. 1989. "Argumentation and Presentation: The Foundation Crisis." Translated by Chris Turner. Cultural Politics 9 (2): 117-43.

Lyotard, Jean-François. 1992. The Inhuman: Reflections on Time. Translated by Geoffrey Bennington and Rachel Bowlby. Stanford, CA: Stanford University Press.

Matthewman, Steve. 2013. "Accidentology: A Critical Assessment of Paul Virilio's Political Economy of Speed." Cultural Politics 9 (3): 280-95.

Mezzadra, Sandro, and Brett Neilson. 2012. “Between Inclusion and Exclusion: On the Topology of Global Space and Borders." In "Topologies of Culture," edited by Celia Lury, Luciana Parisi, and Tiziana Terranova. Special issue, Theory, Culture, and Society 29 (4-5): 58-75.

Milne, Peter W. 2013. “Exceeding the Given: Rewriting Lyotard's Aesthetics." Cultural Politics 9 (2): 107-16.

Redhead, Steve. 2005. "Toward a Theory of Critical Modernity: The Post-Architecture of Claude Parent and Paul Virilio." Topia, no. 14: 37-56.

Sebald, W. G. 1996. The Emigrants. London: The Harvill Press. 
Sebald, W. G. 2001. Austerlitz. New York: Random House.

Sha, Xin Wei. 2012. "Topology and Morphogenesis." In "Topologies of Culture," edited by Celia Lury, Luciana Parisi, and Tiziana Terranova. Special issue, Theory, Culture, and Society $29(4-5)$ : 220-46.

Slade, Andrew. 2007. Lyotard, Beckett, Duras, and the Postmodern Sublime. Oxford: Peter Lang.

Sloterdijk, Peter. 1998. Blasen. Vol. 1 of Sphären. Frankfurt: Suhrkamp.

Sloterdijk, Peter. 1999. Globen. Vol. 2 of Sphären. Frankfurt: Suhrkamp.

Sloterdijk, Peter. 2004. Schäume. Vol. 3 of Sphären. Frankfurt: Suhrkamp.

Sontag, Susan. 1977. On Photography. London: Penguin.
Sontag, Susan. 2004. "Memory as Freeze-Frame: Extracts from 'Looking at War.'" Diogenes 51 (1): 113-18.

Virilio, Paul. 2002. Desert Screen. London: Continuum. Virilio, Paul. 2005. Negative Horizon. London: Continuum.

Virilio, Paul. 2009. Le futurisme de l'instant: Stop-Eject. Paris: Galilée.

Virilio, Paul. 2010. The Futurism of the Instant: StopEject. Translated by Julie Rose. Cambridge: Polity.

\section{Filmography}

London. 1994. Directed by Patrick Keiller. London: BFI Productions.

Enda McCaffrey is professor of French theory and culture at Nottingham Trent University. $\mathrm{He}$ is the author of a number of books, including Octave Mirbeau's Literary and Intellectual Evolution as a French Writer (2000), The Gay Republic: Sexuality, Citizenship, and Subversion in France (2005), and The Return of Religion in France: From Democratisation to Postmetaphysics (2009). He has been working in French theory, philosophy of religion, and French cultural studies for a number of years and has coedited French Cultural Debates (2001) and Existentialism and Contemporary Cinema: A Sartrean Perspective (2011). He is currently working on a new monograph, "Bodies without Organs: French Theory and Sexuality." 
